International Journal of Current Advanced Research

ISSN: O: 2319-6475, ISSN: P: 2319 - 6505, Impact Factor: SJIF: 5.995

Available Online at www.journalijcar.org

Volume 6; Issue 3; March 2017; Page No. 2671-2672

DOI: http://dx.doi.org/10.24327/ijcar.2017.2672.0072

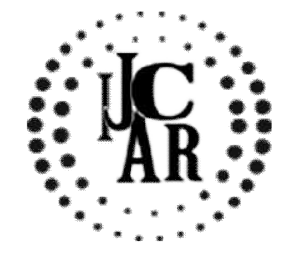

Research Article

\title{
PULMONARY ALVEOLAR MICROLITHIASIS WITH BRONCHIAL ASTHMA
}

\author{
Suhas S Aithal' ${ }^{1}$ Jagmohan SV', Lakshmaiah V3, Prabhakar ${ }^{4}{ }^{4}$ and Abhishek Verma ${ }^{5}$ \\ 1,3,4,5 Dept. of General Medicine, Sri DevarajUrs Academy of Higher Education and Research, Kolar \\ ${ }^{2}$ Dept. of Pulmonology, Sri DevarajUrs Academy of Higher Education and Research, Kolar
}

\section{A R T I C L E I N F O}

\section{Article History:}

Received $27^{\text {th }}$ December, 2016

Received in revised form $17^{\text {th }}$ January, 2017

Accepted $6^{\text {th }}$ February, 2017

Published online $28^{\text {th }}$ March, 2017

\section{Key words:}

Pulmonary alveolar microlithiasis, Bronchial asthma, Black pleura sign

\begin{abstract}
A B S T R A C T
Pulmonary alveolar microlithiasis (PAM) is a rare autosomal recessive disorder characterized by intra-alveolar accumulation of spherical microliths in the absence of any known calcium metabolism disorder. The hallmark of this disorder is clinical-radiological dissociation, meaning that there is a paucity of symptoms in contrast to characteristic imaging findings. At diagnosis, most patients are asymptomatic and changes in the lung parenchyma are found incidentally. As the disease advances patient may develop dyspnea, dry cough, chest pain. There are less than 1050 cases of PAM reported worldwide. We report a rare case of PAM with bronchial asthma.
\end{abstract}

Copyright $₫ 2017$ Suhas $\boldsymbol{S}$ Aithal et al. This is an open access article distributed under the Creative Commons Attribution License, which permits unrestricted use, distribution, and reproduction in any medium, provided the original work is properly cited.

\section{INTRODUCTION}

Pulmonary alveolar microlithiasis (PAM) is a rare autosomal recessive disorder characterized by intra-alveolar accumulation of spherical microliths in the absence of any known calcium metabolism disorder. ${ }^{(1)}$ it's caused due to the mutations of the SLC34A2 gene, which encodes a sodium phosphate co-transporter. The hallmark of this disorder is clinical-radiological dissociation, meaning that there is a paucity of symptoms in contrast to characteristic imaging findings. ${ }^{(2)}$ At diagnosis, most patients are asymptomatic and changes in the lung parenchyma are found incidentally. As the disease advances patient may develop dyspnea, dry cough, chest pain. There are less than 1050 cases of PAM reported worldwide. ${ }^{(3)} \mathrm{We}$ report a rare case of PAM with bronchial asthma.

\section{CASE REPORT}

A 60 year old lady, presented with complaints of exertional dyspnea, cough with scanty mucoid expectoration, wheeze on and off since 5 years, atopy symptoms since childhood. Her vitals were normal at the time of presentation. On examination she had bilateral diffuse rhonchi. A clinical diagnosis of bronchial asthma was made and a chest $X$ ray and PFT were ordered. Chest $X$ ray revealed diffuse sandstorm-like calcifications predominantly in the bilateral middle and lower lung zones. PFT showed restrictive pattern with good reversibility.

*Corresponding author: Suhas S Aithal Dept. of General Medicine, Sri Devaraj Urs Academy of Higher Education and Research, Kolar
HRCT lungs then showed bilateral calcification predominantly in the middle and lower zone with inter and intralobular septal thickening and ground glass opacities with positive black pleura sign. With the characteristic $\mathrm{X}$ ray and CT findings a diagnosis of PAM with bronchial asthma was made. Lung biopsy showed intra alveolar microliths confirming the diagnosis of PAM.
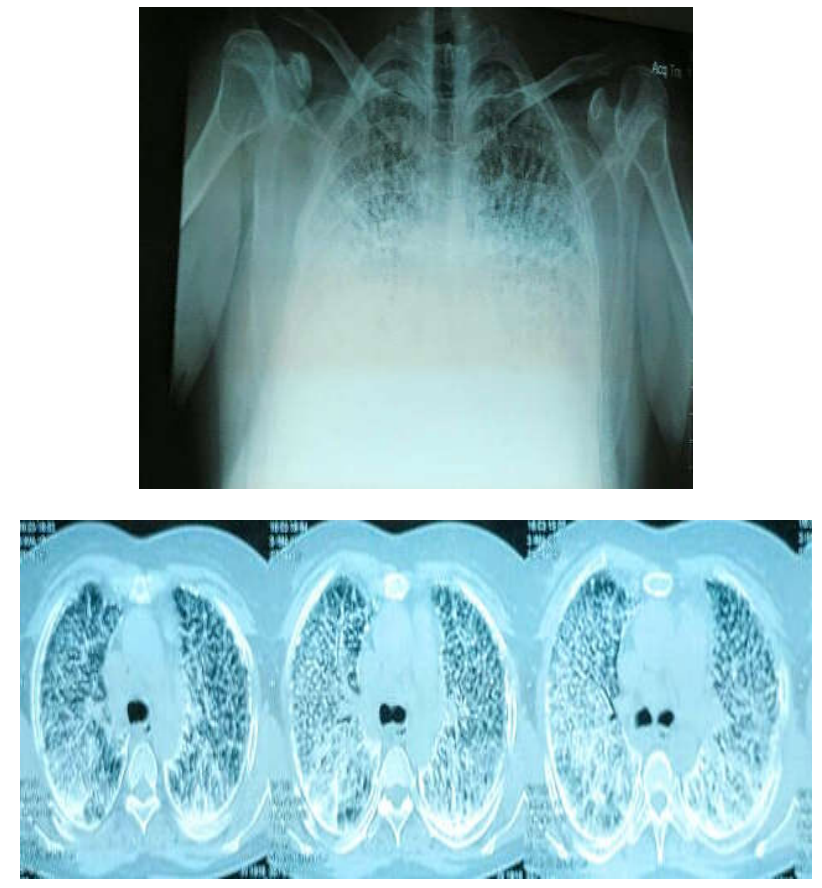


\section{DISCUSSION}

Pulmonary alveolar microlithiasis is a rare disease entity that is characterized by innumerable diffuse calcospherites (microliths composed of calcium and phosphorus) within the alveolar space ${ }^{(1)}$. It is reported worldwide and $25 \%$ cases are from turkey. A slight female predilection may be present in familial form. The disease is usually discovered from birth up to 40 years of age and is often diagnosed incidentally during radiography of the chest for other reasons. Although the etiology remains unclear, PAM is thought to be an autosomal recessive disease caused by mutations of the SLC34A2 gene, which encodes a sodium phosphate co-transporter. ${ }^{(3)}$ PAM has been described in detail by Soaman in 1957. ${ }^{1-10}$

The patients are usually asymptomatic in mild form or may present as dyspnea, dry cough, chest pain and asthenia when the diseases advances. Our patient presented with asthma like symptoms. Respiratory insufficiency eventually progresses to pulmonary fibrosis, end-stage lung disease, and chronic pulmonary heart disease. Extrapulmonary involvement is uncommon ${ }^{(5)}$. The hallmark of this disorder is clinicalradiological dissociation meaning that clinicians will find a paucity of symptoms in contrast to imaging findings. ${ }^{(6)}$

On radiographs PAM is characterized by diffuse fine calcific micronodules that involve both lungs in a pattern that is classically described as sandstorm-like involving the mid and lower zones ${ }^{(6-7)}$. Calcified micronodules, ground-glass opacities, interlobular septal thickening, pleural and subpleural calcification and cysts are typical radiological findings seen in $\operatorname{HRCT}(8)$ As the disease progresses, pulmonary function tests reveal typical features of a restrictive defect with reduced forced vital capacity (FVC) and elevated FEV1/FVC. Reduced total lung capacity and tidal volume $\left(V_{\mathrm{T}}\right)$ have also been described.

There is no known effective treatment for PAM, with the exception of lung transplantation ${ }^{(9)}$ Palliative treatments with systemic corticosteroids, calcium-chelating agents and serial bronchopulmonary lavage have been shown to be ineffective. Attempts to reduce calcium phosphate precipitation in pulmonary alveoli has been tried with diphosphonate ${ }^{(10)}$ The long term prognosis of this disease is poor.

\section{CONCLUSION}

The disease may progress with chronic alveolar calcification causing interstitial inflammation, and fibrosis leading to decreased lung volumes and eventually right heart failure. No treatment has been proven to effectively prevent the progression of PAM. Currently, the only effective therapy is lung transplantation, especially when it is performed before the disease progresses to an advanced stage.

\section{References}

1. Moran CA, Hochholzer L, Hasleton PS, Johnson FB, Koss MN. Pulmonary alveolar microlithiasis: a clinicopathologic and chemical analysis of seven cases. Arch Pathol Lab Med 1997;121(6):607-611

2. Shah MS, Nanavati KI, Airon N, Shah RR, Joshi BD. Case report: Pulmonary alveolar microlithiasis. Indian J Radiol Imaging. 2003; 13:277-9.

3. Corut A, Senyigit A, Ugur SA, et al. Mutations in SLC34A2 cause pulmonary alveolar microlithiasis and are possibly associated with testicular microlithiasis. Am J Hum Genet 2006; 79: 650-656

4. Sosman MC, Dodd GD, Jones WD, Pillmore GV. The familial occurrence of pulmonary alveolar microlithiasis. AJR Am J Roentgenol. 1957; 77:947

5. Tachibana T, Hagiwara K, Johkoh T. Pulmonary alveolar microlithiasis: review and management. CurrOpinPulm Med2009; 15(5):486-490.

6. Shah M, Joshi JM. Bone scintigraphy in pulmonary alveolar microlithiasis. Indian $J$ Chest Dis Allied Sci. 2011; 53:221-3.

7. Melamed JW, Sostman HD, Ravin CE. Interstitial thickening in pulmonary alveolar microlithiasis: an underappreciated finding. J Thorac Imaging 1994; 9(2): 126-128.

8. Dogan OT, Ozsahin SL, Gul E, et al. A frame-shift mutation in the SLC34A2 gene in three patients with pulmonary alveolar microlithiasis in an inbred family. Intern Med 2010; 49: 45-49.

9. Siddiqui NA, Fuhrman CR. Best cases from the AFIP: pulmonary alveolar microlithiasis. Radiographics 2011; 31: 585-590.

10. Göcmen A, Toppare MF, Kiper N, Büyükpamukcu N. Treatment of pulmonary alveolar microlithiasis with diphosphonate: Preliminary results of a case. Respiration. 1992; 59:250-2.

\section{Please cite this article in press as:}

Suhas S Aithal et al (2017), Pulmonary Alveolar Microlithiasis With Bronchial Asthma, International Journal of Current Advanced Research, 6(3), pp. 2671-2672. http://dx.doi.org/10.24327/ijcar.2017. 2673.0072 